\title{
Intelligent energy management control for independent microgrid
}

\author{
T BOGARAJ*'(D) and J KANAKARAJ
}

Electrical and Electronics Engineering Department, PSG College of Technology, Coimbatore 641004, India

e-mail: tbr@eee.psgtech.ac.in; jkr@eee.psgtech.ac.in

MS received 27 May 2015; revised 28 October 2015; accepted 15 February 2016

\begin{abstract}
This work presents a new adaptive scheme for energy management in an independent microgrid. The proposed energy management system has been developed to manage the utilization of power among the hybrid resources and energy storage system in order to supply the load requirement based on multi-agent system (MAS) concept and predicted renewable powers and load powers. Auto regressive moving average models have been developed for predicting the wind speed, atmospheric temperature, irradiation, and connected loads. The structure proposed in this paper includes renewable sources as primary source and storage system as secondary source. A wind generator and solar PV array system together acts as primary source, which supplies power to the local load most of the time in this energy management strategy. When they fail to meet the load demand, the secondary source present in the system will assist the primary source and help to attain the goal of satisfying load demand without interruption. If the primary source and secondary source together are not able to meet the load demand then load shedding will be executed according to the priority set. Thus the developed MAS algorithm co-ordinates the hybrid system components and achieves energy management among renewable energy sources, storage units, and load under varying environmental conditions and varying loads. STATCOM based compensation has been implemented to balance the reactive power demand and to mitigate the voltage fluctuations and harmonics on the AC bus. The proposed microgrid has been simulated with MAS concept in Matlab/Simulink environment. The results presented in this paper show cases the effectiveness of the proposed energy management controller.
\end{abstract}

Keywords. Energy management control; multi-agent system; microgrid; energy forecast; hybrid power system; power quality issues.

\section{Introduction}

Renewable energy sources are being actively sought after to augment the electricity production nowadays because of Kyoto Protocol restrictions on generation of greenhouse gases, increase in price of fossil fuels, and depletion of fossil fuel reserves [1]. Many remote and rural areas all over the world are not connected to electricity grid even now. One of the important utilization of the renewable energy system is to electrify remote villages, rural areas and rugged terrain located outlying from power distribution networks [2]. The drawbacks of renewable energy sources are the dependency of energy production on weather conditions and unpredictable climatic changes.

For powering stand-alone applications, combining two or three renewable energy sources provides an interesting and reliable solution [3]. Integration of few renewable energy systems for electricity production is called as hybrid power system (HPS). Energy management in such systems is quite complex because of continuous change in the energy

*For correspondence production by renewable energy sources, continuously varying loads and many systems that are to be controlled $[4,5]$. Operation of independent microgrid requires appropriate load sharing mechanisms to balance sudden active power mismatches, and is considerably more challenging than the grid-connected mode [6]. A better solution for the energy management in HPS is provided by using multi-agent systems (MASs) control in which each system in HPS is controlled by one agent. The agents are nothing but software entities established with simple rules pertaining to one subsystem in HPS. Each element in HPS has its own control and manipulating variables. Agents communicate with other agents and collect data from other elements, process the data and make decisions. MAS adapt the 'bottom-up' approach, in which elements of HPS are monitored and controlled separately by each agent [1].

In the classical centralized system, the controller receives the status of elements and based on those information it manages energy flow. Such controllers are based on topdown approach and require lengthy programme coding. Also if the central controller is not functioning because of some error, the entire system becomes dysfunction. Even 
for including a few elements to upgrade the system, the controller programme needs to be rewritten completely for new situation. Such controllers have more time delay in taking decisions than MAS based controller, because one controller has to make all measurements and calculations.

\section{Related literature}

MAS control is being applied in the present scenario for the distributed microgrid by many researchers. Inherent distributed architecture of MAS makes it suitable to apply for the distributed microgrid. The HPS microgrid may be operated in stand-alone or grid connected mode. Different combinations of HPS configurations and different objectives for the optimal operation were considered in literature. MAS control for a PV/battery/fuel cell/super capacitors stand-alone HPS was proposed [2]. A MAS based control has been presented for a grid connected PV, battery, super capacitor (SC) HPS. Super capacitor is used because it can handle sharp load changes and longer life. The agents have the objective of minimizing the power supplied by it [1]. The MAS algorithm proposed for a microgrid system which includes PV, fuel cell, battery, composite energy storage system (CESS), diesel generator, and grid. The objective of the control is to maximize utilization of renewable energy sources and minimizes the diesel consumption [7]. Two-level MAS controller scheme used for a PV/wind/battery/fuel cell/microturbine generating system $[4,5,8]$. First level optimizes the operation of microgrid by coordinating and negotiating among distributed energy sources. Second level makes decisions in such a way that the sources are producing optimal dispatch [8]. A MAS control algorithm to reduce the production cost and deviation of power between renewable source and load has been implemented in a PV/ wind/battery hybrid microgrid [9]. A simulation study on MAS control for DC-coupled photovoltaic (PV), fuel cell (FC), ultracapacitor (UC) and battery HPS microgrid for commercial buildings and apartment buildings has been presented. The system is operated in grid connected or stand-alone modes [10]. A MAS based power sharing scheme was proposed for a PV/fuel cell/battery HPS, and simulation studies were conducted in the virtual test bed (VTB) environment [11]. Energy management and power regulation system (EMPRS) proposed for a wind/battery/fuel cell stand-alone system. The algorithm manages the energy flows and executes load shedding algorithm under worst wind conditions. The simulations were carried out in Matlab [12]. A four-level hierarchical control framework (HCF) and a MAS based decentralized control strategy named hybrid multi-agent control model (HAM) was proposed for renewable energy microgrid. The test system is not the actual microgrid, it is approximated laboratory test bed system [5].
Assistance from forecasting of renewable sources and loads will help the microgrid to assess the renewable energy power in advance and to achieve better demand side management [13]. ARMA model for forecasting of solar irradiation from historical solar data is preferred for short and medium time prediction in microgrid level [13]. It is quite appropriate to use ARMA model of times series to forecast the wind speed, because the wind speed has very good succession and randomness [14].

In independent microgrid, power quality issues such as harmonics due to nonlinear loads and voltage fluctuations due to sudden switching of loads are listed as major issues in literature. Passive power filters, active power filters, Multifunctional VSIs, or FACTs devices are employed to address these issues in independent microgrid. In literature many studies presented the employment of shunt active power filters for compensating harmonics and voltage fluctuations $[6,15-19]$. Voltage imbalance and harmonic reduction is mitigated by the inverter operating as shunt active power filter in a DG environment [20]. A current controlled VSI is used to maintain the voltage balance [21]. A VSI inverter performs functions of a D-STATCOM and a distributed APF in power distribution networks and provides the required compensating currents in all conditions [22]. VSC based D-STATCOM is commonly accepted for power quality improvement under varying nonlinear loads [23]. STATCOM can compensate reactive power flexibly and also, its response time is superior to the other conventional methods [24].

In this paper MAS based energy management and load shedding (MEMLS) control is proposed for a stand-alone $\mathrm{PV} /$ wind/fuel cell/battery HPS microgrid shown in figure 1 . The proposed MAS has been designed to optimize the extraction of the maximum power from $\mathrm{PV}$ and wind sources, utilization of power generated from PV and wind sources, life time of storage units, and load management. The algorithm developed in two levels. The first level is control of individual subsystems in the HPS microgrid. The second level is the energy management and load shedding, which controls the power flow among renewable sources, storage systems and load. The energy management is achieved by comparing the predicted and actual powers from sources, connected load and present energy available in storage units. A STATCOM based reactive power compensation method is proposed to mitigate harmonics and better reactive power management. Matlab provides solution for many electrical and power system related problems [2]. The system models and MAS controller have been developed in Matlab/Simulink.

\section{MAS technology for HPS}

MAS has been successfully applied in many fields like telecommunication, manufacturing, transportation, etc. in the last three decades. From last two decades it is employed in electrical field also [2]. 


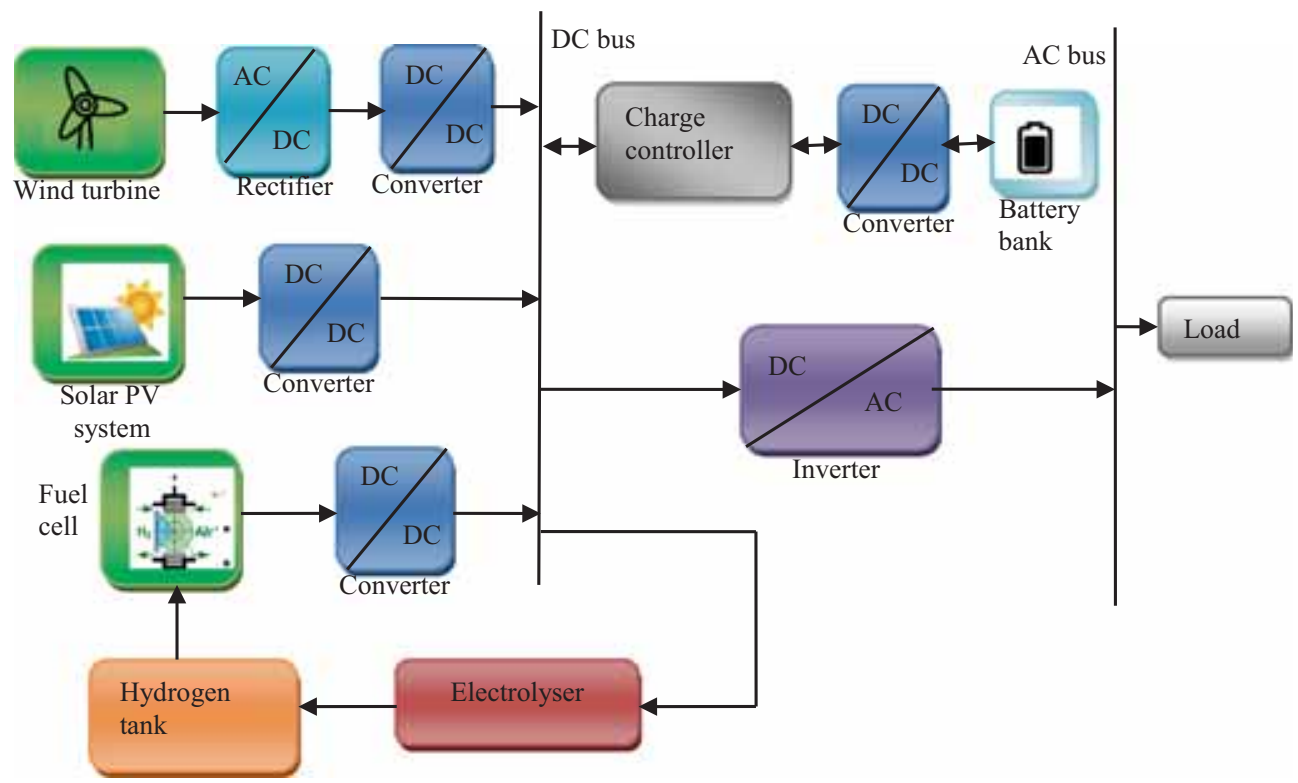

Figure 1. Proposed environment for implementing MAS technology.

The specific characteristics which could describe agent's behavior are

- The agents of the MAS algorithm have certain amount of control over the system.

- Agents will react when the environment exhibits changes.

- Agents make forehanded decisions.

- Agents communicate among them and the central controller.

Multi-agent technology is a method to achieve a distributed and difficult task by means of agent's collaboration and communication [2]. Agent is nothing but software entities which has self-adaptation capability and intelligence to accomplish a complicated task [25]. So the agent is an entity which has independent problem-solving ability and is responsive to a changing environment [26]. MAS consists of many interacting agents that together accomplish a complicated task on the basis of communication and cooperation so as to optimize a system $[2,27]$. To share information with other agents and central controller, agents write information in a common place (Memory). Agents that need information, read the status of other agents from this common place. Agents have capabilities such as making decision for the individual control and communication with other agents and central controller [26]. With MAS, each subsystem's control unit in a microgrid is designed as an agent. The operation of the microgrid is implemented through intelligent decisions and collaborations of these agents [4].

The goals of the MAS control applied to hybrid microgrid are:
- To supply power to the load to the extent possible

- To maximize the overall efficiency of HPS system

- To increase the utilization of available natural energy from renewable energy sources

- To increase the lifetime of storage devices by minimizing the number of switchings

\section{Proposed hybrid microgrid architecture}

The proposed microgrid as represented in figure 1 has two renewable power generation systems, solar PV system and a wind generating system. It also has fuel cell and battery bank as secondary sources (backup). Hence the PV and wind turbine are used as the main power generation system, the fuel cell and the battery bank are assigned as backup power generators for providing continuous power supply to the load [28]. To satisfy the load continuously, storage devices will act as source, when they have enough power. When excess power is available from primary sources, storage devices will act as load, when charge in them is less than maximum limit.

TitanS6_60 solar panels have been modeled for $100 \mathrm{~kW}$ output power at nominal operating cell temperature and irradiation [29]. Twenty-four solar panels have been connected in series and 20 such strings have been connected in parallel. Totally 480 panels have been used for constructing the solar PV system. A PMSG type generator rated for $200 \mathrm{~kW}$ has been modeled for wind generating system. The batteries are sized for $100 \mathrm{~kW}$ whereof 72 batteries of 120 $\mathrm{Ah}$ were connected in series, which can store $300 \mathrm{kWh}$ of energy. The connected load to the system has been 
considered as $80 \mathrm{~kW}$ maximum with three parts such that the base load of $40 \mathrm{~kW}$ peak and two additional loads of $20 \mathrm{~kW}$ peak each. Fuel cell is of PEMFC type and considered for $100 \mathrm{~kW}$ capacity. An electrolyser is also modeled for the capacity of $100 \mathrm{~kW}$. A hydrogen tank of $2 \mathrm{~m}^{3}$ capacity is considered to store the generated hydrogen. A dump load of $50 \mathrm{~kW}$ (may be a heating load/any low priority load) is also connected in order to manage the excess RES power and avoid system break down especially in wind generating system.

\section{Agents for proposed hybrid microgrid}

The control and information flow in the MAS environment for the proposed hybrid microgrid is shown in figure 2 .

The following are the agents are developed for the control of elements in HPS considered:

Agent 1: Wind energy conversion system

Agent 2: Solar PV system

Agent 3: Battery energy storage system

Agent 4: Fuel cell system

Agent 5: Load
MEMLS controller The controller has been developed to make decision and achieve its ultimate goal based on the information received from the corresponding agents and the forecasted power situation.

\subsection{Wind generator model and agent}

The power output of wind turbine can be stated as $[29,30]$

$$
P w=\frac{1}{2} \rho A C_{p}(\lambda, \beta)\left[\frac{R \omega_{o p t}}{\lambda_{\text {opt }}}\right]^{3}
$$

where $\rho$ is the air density $\left(\rho=1.225 \mathrm{~kg} / \mathrm{m}^{3}\right), R$ is the blade length, $A$ is swept area of the blade, $\omega_{\text {opt }}$ is the optimum speed of wind turbine and $\lambda_{\text {opt }}$ is the optimum tip-speed ratio. The power coefficient $C_{p}$ depends on the pitch angle $\beta$ and the tip speed ratio $\lambda$ and is given by

$$
\lambda=\frac{\omega R}{V_{w}}
$$

where $\omega$ is the rotational speed of the wind turbine and generator and $V_{W}$ is the wind speed. The power coefficient $C_{p}$ is given by the expression

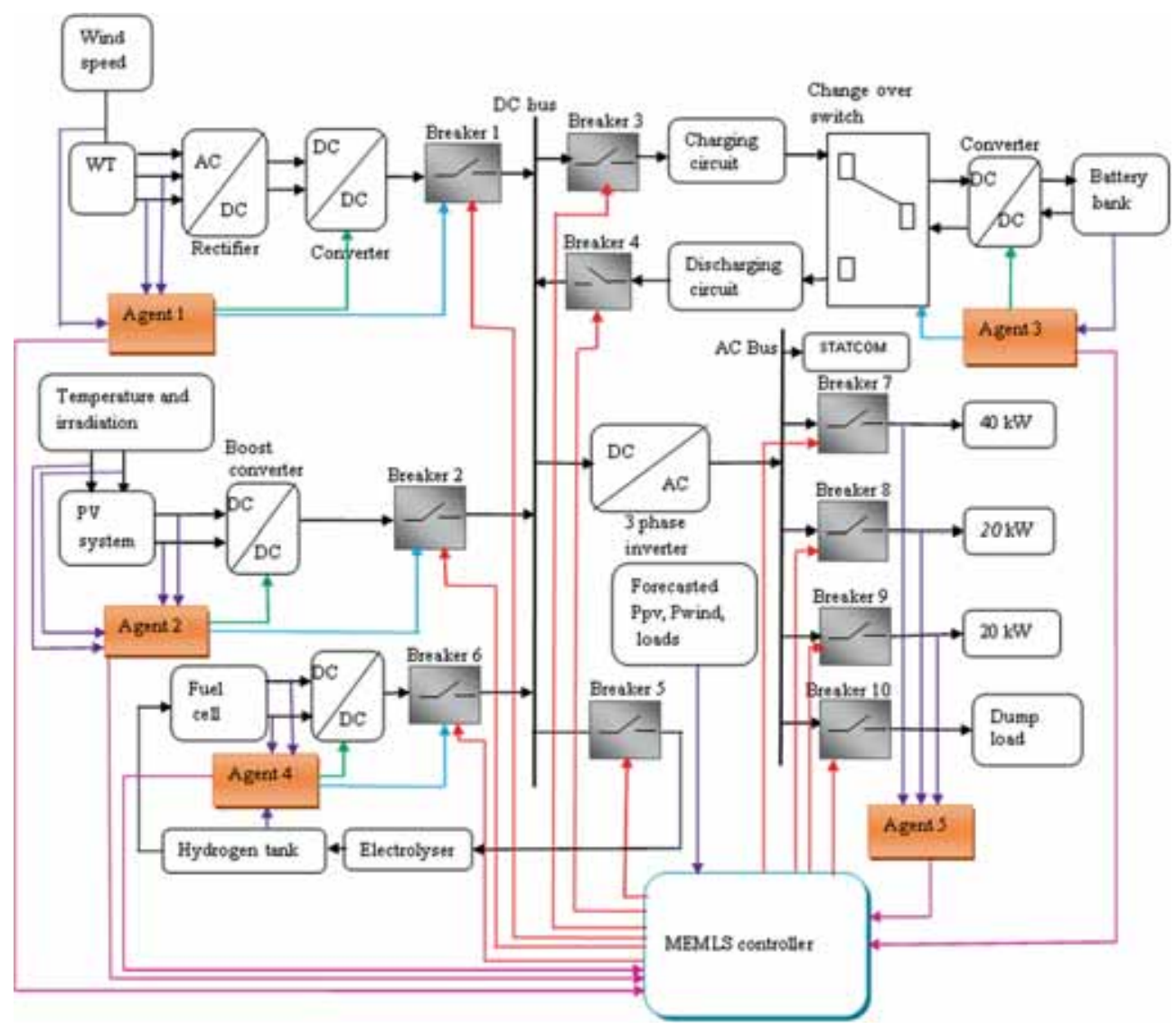

Figure 2. Implemented MAS control flow in proposed HPS environment. 


$$
\begin{array}{r}
C_{p}(\lambda, \beta)=0.5\left(116 \frac{1}{\delta}-0.4 \beta-5\right) e^{-21 \frac{1}{\delta}} \\
\text { with } \frac{1}{\delta}=\frac{1}{\lambda+0.08 \beta}+\frac{0.035}{1+\beta^{3}} .
\end{array}
$$

Algorithm for wind agent is given in figure 3. The agent will send the signal to Breaker 1 to close if the wind speed is within range and also generate necessary duty cycle for the DC-DC converter to achieve MPPT.

\subsection{Solar PV system model and agent}

A solar PV cell converts sunlight into DC power. For an operating condition, the short-circuit current $\left(I_{s c}\right)$ and the open-circuit voltage $\left(V_{o c}\right)$ of the $\mathrm{PV}$ module are written as [30]

$$
\begin{gathered}
I_{s c}=I_{s c 0}\left(\frac{G}{G_{0}}\right)^{\alpha} \\
V_{o c}=\frac{V_{o c 0}}{1+\beta \ln \left(\frac{G_{0}}{G}\right)}\left(\frac{T_{0}}{T}\right)^{\gamma}
\end{gathered}
$$

where $G_{0}, G$ are standard and operating solar irradiance of PV module; $I_{s c 0}, I_{s c}$ are the short-circuit currents of the PV module at $G_{0}, G$ respectively; and $\alpha$ is the constant accountable for the nonlinear effects of photocurrent. $T_{0}$, $T$ are standard and operating temperatures of PV Module; $V_{o c 0}$ and $V_{o c}$ are the open-circuit voltages of the PV module at $\left(G_{0}, T_{0}\right)$, and $(G, T)$ respectively; $\beta$ is a dimensionless coefficient related to PV module technology and $\gamma$ is the exponent for all the temperature-voltage nonlinear effects.

Maximum output power of a PV module, $P_{\max }$, is given by

$$
\begin{aligned}
P_{\max }= & \frac{\frac{q V_{o c}}{a k T}-\ln \left(\frac{q V_{o c}}{a k T}+0.72\right)}{1+\frac{q V_{o c}}{a k T}} \times\left(1-\frac{R_{s}}{V_{o c} / I_{s c}}\right) \times\left(\frac{T_{0}}{T}\right)^{\gamma} \\
& \times\left(\frac{V_{o c 0}}{1+\beta \ln \left(\frac{G_{0}}{G}\right)}\right) \times I_{s c 0}\left(\frac{G}{G_{0}}\right)^{\alpha}
\end{aligned}
$$

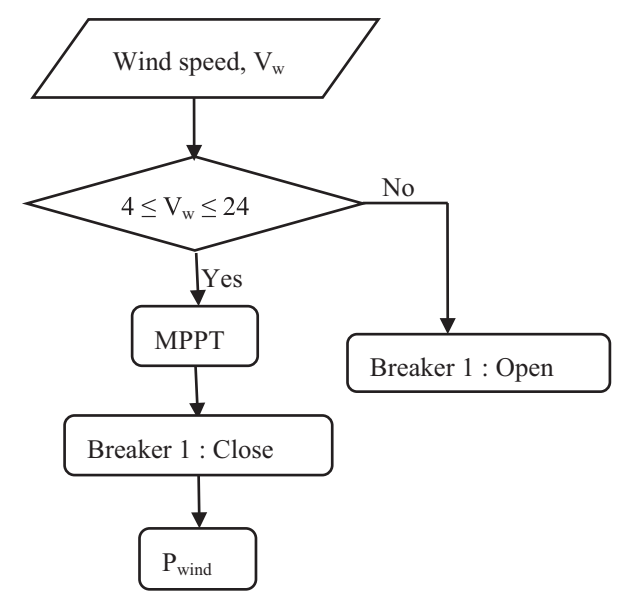

Figure 3. Algorithm for agent 1-wind energy conversion system. where $a$ is ideality factor $(1<a<2), R_{s}$ is the series resistance of the cell, $k$ is Boltzmann constant $\left(1.38 \times 10^{-23} \mathrm{~J} /{ }^{\circ} \mathrm{K}\right)$, and $q$ is the charge of an electron.

A number of solar cells are connected in series to provide desired output voltage. Many such arrangement are connected in parallel to form a solar module, to increase the output current. Voltage, current and power of a PV array with $N_{s}$ (Number of series modules) $\times N_{p}$ (Number of parallel strings) modules are calculated as

$$
\begin{gathered}
I_{A}=N_{p} \times I_{M} \\
V_{A}=N_{s} \times V_{M} \\
P_{A}=N_{p} \times N_{s} \times P_{M},
\end{gathered}
$$

where $V_{A}, V_{M}, I_{A}, I_{M}, P_{A}$ and $P_{M}$ are voltages of PV array and module, currents of PV array and module, and powers of PV array and module, respectively.

The algorithm for solar PV agent is given in figure 4. This agent controls the switching of breaker 2 according to solar irradiation and temperature. If they are out of range the breaker is opened, otherwise it is closed. Also it achieves the MPPT of solar PV system by sending appropriate duty cycle to DC-DC converter.

\subsection{Battery model and agent}

The objective of the battery agent is to charge and discharge the battery according to available renewable source power, SOC, and load demand.

The SOC of the battery is given by $[31,32]$

$$
S O C=S O C_{0}+\int_{t 0}^{t}\left(\frac{I_{b a t}}{C a p_{b a t}}\right) \mathrm{d} t
$$

where $C_{a p} p_{b a t}$ is battery capacity (Ah) and $I_{b a t}$ is the battery current (A).

The algorithm for the battery agent is represented in figure 5. Battery agent controls the changeover switch either to charge or discharge the battery and sends the duty cycle command to DC-DC converter.

\subsection{PEMFC model and agent}

The fuel to PEMFC has been provided by the hydrogen tank which has been designed to store the hydrogen produced by the electrolyser. The electrolyser in turn gets its input from the dc bus. The fuel cell parameters such as open circuit voltage $\left(E_{O c}\right)$, the exchange current $\left(I_{c}\right)$ and the Tafel slope $(A)$ are depend on variations in temperature, pressures, compositions and flow rates of fuel and air. Therefore to calculate the fuel cell parameters the formulae used are [33]: 


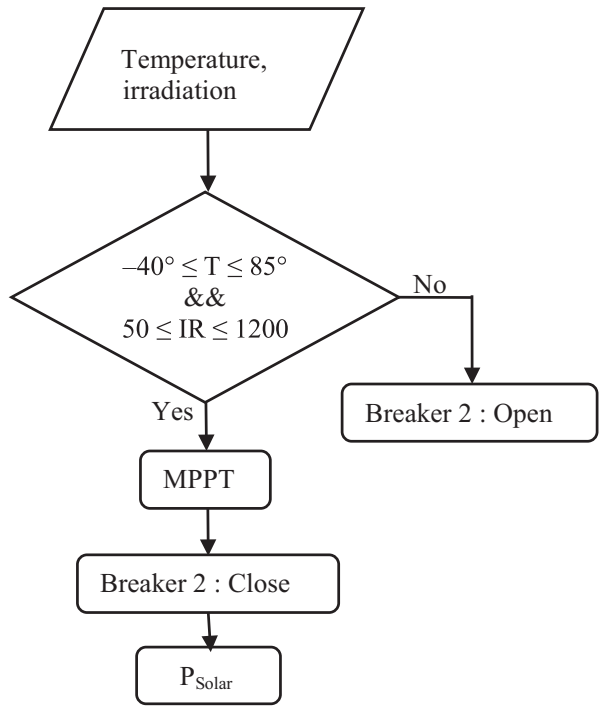

Figure 4. Algorithm for agent 2-solar PV system.

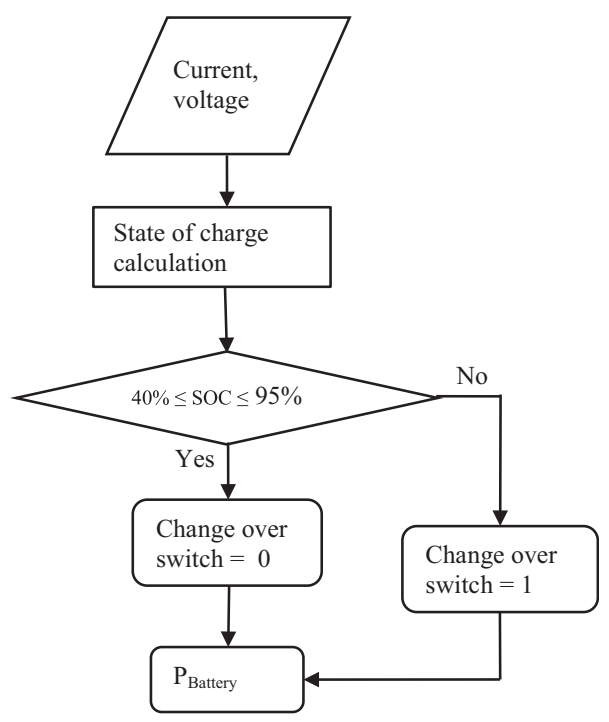

Figure 5. Algorithm for agent 3-battery system.

$$
V_{f c}=\left(E_{o c}-N A \ln \left(\frac{I_{f c}}{I_{c}}\right) \times \frac{1}{s \frac{T_{d}}{3}+1}\right)-R I_{f c}
$$

where

$$
\begin{gathered}
E_{o c}=K_{c} E_{n} \\
I_{c}=\left(\frac{z F k\left(P_{H_{2}}+P_{O_{2}}\right)}{R h}\right) e^{\left(\frac{-\Delta G}{R T}\right)} \\
A=\frac{R T}{z \alpha F},
\end{gathered}
$$

where $K c$ is voltage constant at nominal condition of operation, En is Nernst voltage, which is the thermodynamics voltage of the cells and depends on the temperature and partial pressure of reactants and products inside the stack $(\mathrm{V})$, $R$ is universal gas constant $(8.3145 \mathrm{~J} /(\mathrm{mol} \mathrm{K})), F$ is Faraday's constant (96485 A s/mol), $z$ is number of moving electrons, $\alpha$ is charge transfer coefficient, $T$ is operating temperature $(\mathrm{K}), P_{H 2}$ is partial pressure of hydrogen inside the stack (atm), $P_{O 2}$ is partial pressure of oxygen inside the stack (atm), $k$ is Boltzmann's constant $\left(1.38 \times 10^{-23} \mathrm{~J} / \mathrm{K}\right)$, $h=$ Planck's constant $\left(6.626 \times 10^{-34} \mathrm{~J} \mathrm{~s}\right)$, and $\Delta G$ is size of the activation barrier which depends on the type of electrode and catalyst used. The agent 4 for fuel cell unit works on the algorithm as represented in figure 6 .

\subsection{Load agent}

The load agent has only one goal (i.e.,) to inform the present load demand to the MEMLS controller by adding up the entire load and give it as a total load to central controller as represented in figure 7 , so that the controller takes corresponding decisions by closing and opening of the breaker to satisfy the load without interruption. The load is considered as base load of $40 \mathrm{~kW}$ peak, which always needs to be satisfied and additional load in two groups of $20 \mathrm{~kW}$ peak each. So the maximum connected load is $80 \mathrm{~kW}$ peak.

\section{MAS based energy management and load scheduling (MEMLS) algorithm}

The proposed MEMLS algorithm has to ensure the continuous supply to the priority load by the coordination of RES, ESS and loads. The algorithm predicts the PV Generation, wind generation, and load demand for a specified short time of $10 \mathrm{~min}$ ahead in the first step. Then it assesses the load that can be supplied during that time based on generation profile and load profile in the second step. In the third step it decides the operating conditions of each HRES subsystem. The major difference in this algorithm is the load management is performed based on forecasting of generation and consumption and the conditions prevailing in the system. This algorithm also executes load shedding if the RES power is lesser than load demand and maintains the supply to most priority load. The stable operation of the system requires prediction of generated powers and load demand. The algorithm developed with forecasting of generated powers and load, enables the load scheduling in advance which is helpful to avoid the blackouts in the system and improves the reliability of the supply.

\subsection{Forecasting of wind, solar, and load for HPS}

Statistical methods such as auto regressive (AR), auto regressive moving average (ARMA), auto regressive integrated moving average (ARIMA), Bayesian approach, and 


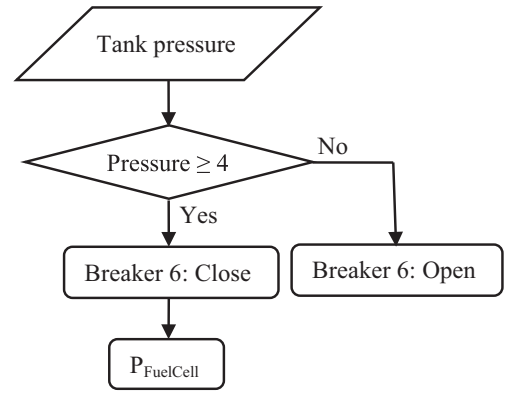

Figure 6. Algorithm for agent 4-fuel cell.

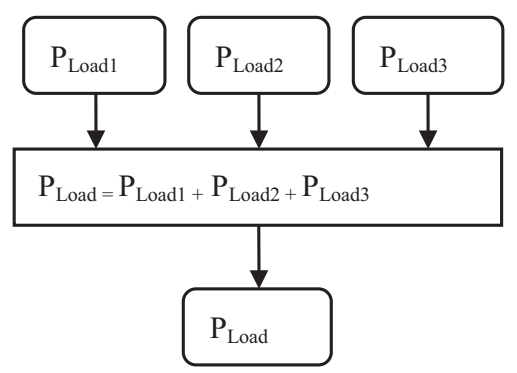

Figure 7. Algorithm for agent 5-load.

gray predictions can be used to solve problems in engineering, economics and natural sciences that have a great deal of data [14]. In this paper the ARMA model has been used to forecast wind, solar irradiation, atmospheric temperature and load connected with the system. The data during the year 2011 have been used for determining the coefficients of the ARMA model for wind speed, solar irradiation, atmospheric temperature $[13,14]$. The data considered are corresponding to the place Coimbatore, Tamilnadu, India which is located $11.0183^{\circ} \mathrm{N}$ longitude and $76.9725^{\circ} \mathrm{E}$ latitude. The load data considered are L1, L2, and L3 varying within the peaks of $40 \mathrm{~kW}, 20 \mathrm{~kW}$ and $20 \mathrm{~kW}$ respectively. The random variations of loads are generated intentionally within the peak limits to realise the model parameters of loads.

The ARMA model considered in this paper is written as follows $[13,14,38,39]$ :

$$
Y_{t}=\sum_{j=0}^{p} a_{j} Y_{(t-j)}+\sum_{i=0}^{q} b_{i} e_{(t-i)}
$$

where $Y_{t}$ is the output at time $t . a_{j}, b_{i}$ are the parameters to be estimated. $p$ is the number of previous output terms on which the current output depends (autoregressive process). $q$ is the number of previous error terms on which the current output depends (moving-average error term). $r$ is the number of input samples that occur before the inputs affecting the current output.

By using the ARMA ( $p=3, q=4, r=1)$ model $[13,14,34]$ the coefficients of the model are found for the above mentioned parameters and are listed in table 1 . The model parameters are found by using the constraint of $5 \%$ mean square error.

\subsection{MEMLS algorithm}

The power balance of the HRES system based on the forecasted PV, wind and load powers can be written as

$$
P_{\text {load }}=P_{R E S}-P_{E l}+P_{F C} \pm P_{B},
$$

where $P_{R E S}=P_{P V}+P_{\text {Wind }} ; P_{P V}$ is the PV power, $P_{\text {Wind }}$ is the wind power, $P_{\text {load }}$ is the load power, $P_{E l}$ is the electrolyser power consumption to generate hydrogen, $P_{F C}$ is the fuel cell power and $P_{B}$ is the battery power in which '-' indicates charging and ' + ' indicates discharging.

For executing load curtailment the loads are grouped into three categories by their priority namely $L 1, L 2$ and $L 3$. So that the total load on the system is

$$
P_{\text {load }}=L 1+L 2+L 3 .
$$

The MEMLS has to manage the load with renewable energy sources and storage systems within the allowable limits of the subsystems. If wind and solar powers are high, the load is easily met and excess power is used to charge battery and/or produce hydrogen. Under low wind and solar conditions, the deficit power to meet the load is supported by battery and fuel cell. Normal operating range of battery is with SOC 40-95\% and fuel cell can produce power if the hydrogen pressure limits of 4-24 MPa. The implemented energy management algorithm is shown in figure 8 is described as below.

1. Calculate the difference in RES generated power and load demand

$$
P_{\text {diff }}=P_{R E S}-P_{\text {load }} .
$$

2. If $P_{\text {diff }}>0$, means excess power is available from RES. Check the SOC of the battery and hydrogen pressure. If Battery SOC $<70 \%$ and hydrogen pressure less than 4 $\mathrm{MPa}$, some non-priority loads to be cut off and excess power send to storage devices. This will enable the system to maintain the SOC and hydrogen reserves to use during nonproduction durations due to worst environmental conditions or failure of subsystems. Otherwise all the loads are powered.

3. If $P_{\text {diff }}<0$, status of SOC of the battery and hydrogen pressure are measured. If the $S O C>70 \%$ and hydrogen pressure is greater than $4 \mathrm{MPa}$, loads can be supplied as follows.

- Check $P_{B(S O C>70 \%)} \geq P_{\text {diff }}$. If yes the load is supplied from RES and battery power.

- If not check $P_{F C} \geq P_{\text {diff }}$. If yes load is supplied from RES and fuel cell power. 
Table 1. ARMA model coefficients.

\begin{tabular}{|c|c|c|c|c|c|c|c|c|c|c|c|}
\hline \multicolumn{2}{|c|}{ Wind speed } & \multicolumn{2}{|c|}{ Temperature } & \multicolumn{2}{|c|}{ Irradiation } & \multicolumn{2}{|c|}{ Load 1} & \multicolumn{2}{|c|}{ Load 2} & \multicolumn{2}{|c|}{ Load 3} \\
\hline$a_{j}$ & $b_{i}$ & $a_{j}$ & $b_{i}$ & $a_{j}$ & $b_{i}$ & $a_{j}$ & $b_{i}$ & $a_{j}$ & $b_{i}$ & $a_{j}$ & $b_{i}$ \\
\hline 0.497 & 0.241 & 0.094 & 0.161 & 0.786 & 0.513 & 0.61 & 0.184 & 0.159 & 0.159 & 0.845 & 0.558 \\
\hline 0.218 & 0.675 & 0.164 & 0.754 & 0.045 & 0.308 & 0.135 & 0.027 & 0.88 & 0.88 & 0.34 & 0.094 \\
\hline 0.471 & 0.489 & 0.242 & 0.187 & 0.297 & 0.5 & 0.028 & 0.091 & 0.135 & 0.135 & 0.017 & 0.111 \\
\hline & 0.077 & & 0.191 & & 0.368 & & 0.065 & & 0.057 & & 0.138 \\
\hline
\end{tabular}

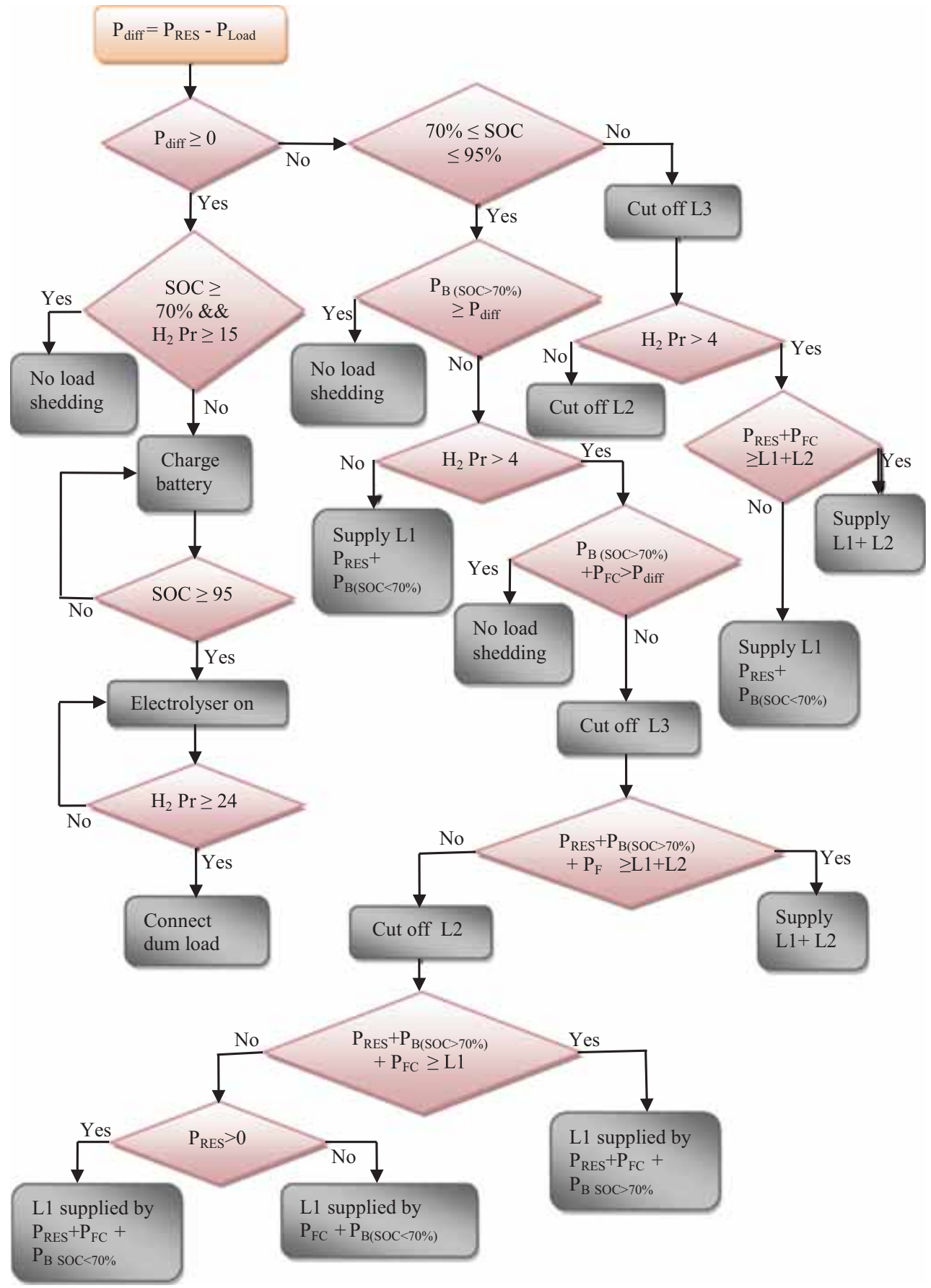

Figure 8. Algorithm for central controller. 
- If not check $P_{B(S O C>70 \%)}+P_{F C} \geq P_{\text {diff }}$. If yes the load is powered with RES along with battery and fuel cell power. If not check $P_{R E S}+$ $\left.P_{B(S O C}>70 \%\right)+P_{F C} \geq L 1+L 2$. If yes Load 1 and Load 2 are supplied with RES + battery + fuel cell power. If not check $P_{R E S}+P_{B(S O C>70 \%)}+$ $P_{F C} \geq L 1$. If yes Load 1 is met with RES + battery + fuel cell power.

4. If $P_{\text {diff }}<0$ and $S O C<70 \%$, load shedding is executed and only load 1 is supplied with reserve power in battery. The reserve power is sufficient to manage load 1 for $7 \mathrm{~h}$, even if wind and solar power is not present. During this condition any RES power generation available could be used for hydrogen production.

\section{Results and discussion}

The proposed MAS algorithm has been simulated in Matlab/Simulink platform. For observing the behavior of proposed algorithm with changing environmental and load conditions, two set of environmental input data obtained during two days with different weather conditions in Coimbatore region, Tamil Nadu, India had been considered. For Case 1, a day in which high wind and high irradiation and for Case 2, a day in which low wind and low irradiation are considered.

\subsection{Case 1: High wind and high irradiation}

In this case, the predicted wind speed is varying in the range $8 \mathrm{~m} / \mathrm{s}$ to $14 \mathrm{~m} / \mathrm{s}$, so that more wind power is available. Irradiation is high; correspondingly solar PV power output is also high on this day. Figure 9(a) and figure 9(b) represents the variation of both predicted and actual wind speed and corresponding output power. It is observed that when wind speed is within the range, WECS is generating corresponding power with respect to wind speed. When the wind speed seems to be out of range the breaker 1 is opened and WECS is isolated.

The predicted and actual temperature, irradiation level and the solar PV output power are represented in figure 10(a), (b) and (c) respectively. As per proposed algorithm for agent 2, the breaker 2 gets opened when both irradiation and temperature are out of range i.e. the solar photovoltaic power output is not up to the required level. Figure 11 represents forecasted and actual load duration curve of the loads L1, L2, L3 and total load. The MEMLS controller will take decision to charge the battery and/or hydrogen generation depending on the $P_{\text {diff. }}$ The predicted wind generator power, solar PV power, total available power from the system i.e. summation of wind power, solar PV power, load power and $P_{\text {diff }}$ are plotted in figure 12 . Here, $P_{\text {diff }}$ is positive most of the times, which is used to save energy in storage devices and the load is easily met. Figure 13(a) and (b) represents the battery power and battery SOC respectively. During this operation, the battery is getting charged and SOC is increasing. But $P_{\text {diff }}$ is more than the required charging power for battery during $10.10 \mathrm{~h}$ to $14.50 \mathrm{~h}$. Hence the electrolyser is operated to generate hydrogen during this period to consume excess RES power. Power utilized by Electrolyser and hydrogen pressure variation are shown in figure 14(a) and (b) respectively. Battery bank is getting charged for most of the duration on this day and is discharged for very less duration.

\subsection{Case 2: Low wind and irradiation}

In Case 2, a day during spring season is considered in which irradiation and wind speed are of moderate values. Figure 15(a) represents the forecasted wind speed and actual wind speed. Respective predicted and actual wind generated power are shown in figure 15(b). It is observed that the average wind speed is about $6 \mathrm{~m} / \mathrm{s}$. So the power production in wind generator is lesser than its full capacity. The forecasted and actual temperature variation, irradiation and corresponding solar PV power are represented in

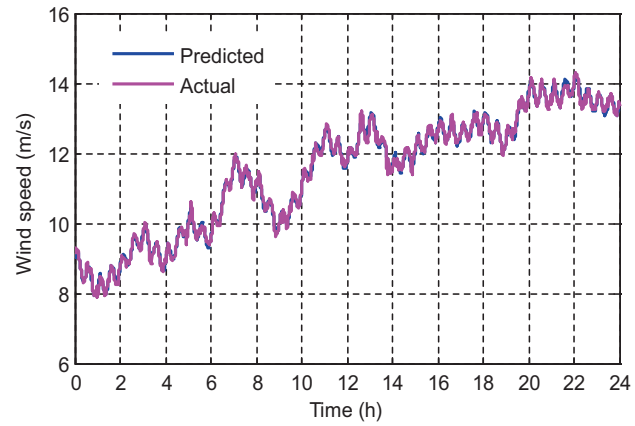

(a)

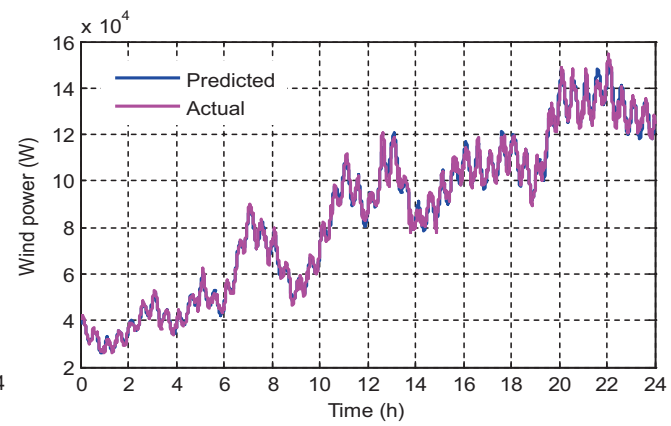

(b)

Figure 9. Wind energy conversion system (a) wind speed variation and (b) generated power. 


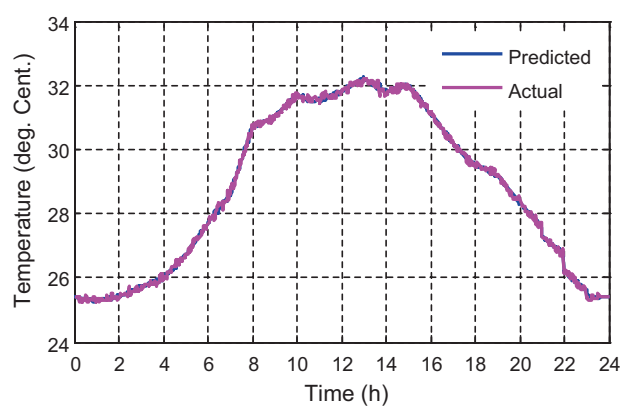

(a)

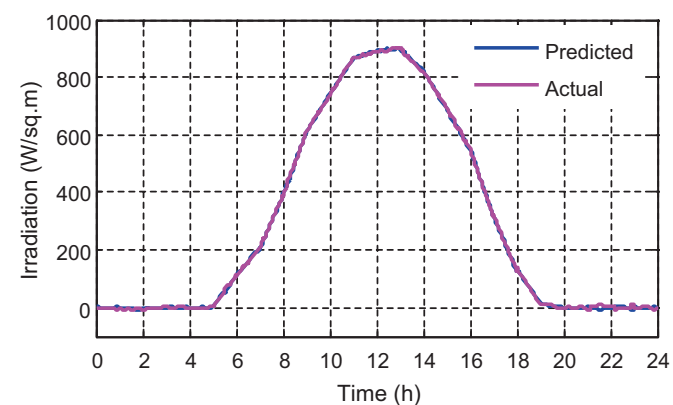

(b)

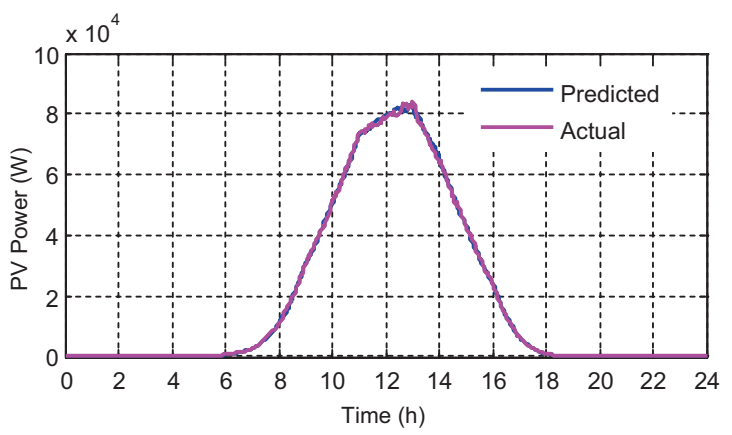

(c)

Figure 10. Solar PV system (a) temperature variation, (b) irradiation level and (c) generated power.

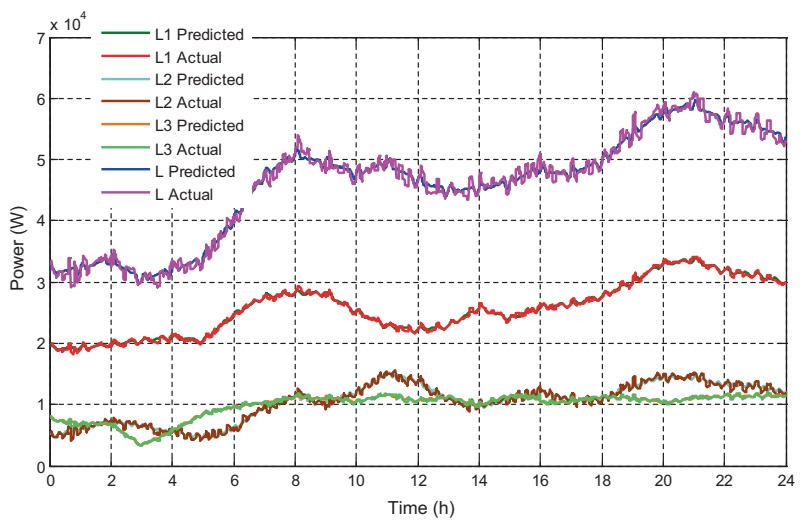

Figure 11. Load power.

figure 16(a), (b) and (c) respectively. The solar irradiation is also less on this day and power production is less. The predicted and actual load powers L1, L2, L3 and the sum $\mathrm{L} 1+\mathrm{L} 2+\mathrm{L} 3$ are shown in figure 17.

In figure 18, the predicted PV power, wind power, total RES power and load power and $P_{\text {diff }}$ are shown. Here the predicted wind and solar PV generated powers are less than the load. SOC of the battery is above $70 \%$ up to $2 \mathrm{~h}$ and 50 min shown in figure 19(b). Till this time the whole load is supplied by RES + battery power. After $2 \mathrm{~h}$ and $50 \mathrm{~min}$ the SOC goes lower than 70\%, which corresponds to reserve power. At this time L3 is cut off as shown in

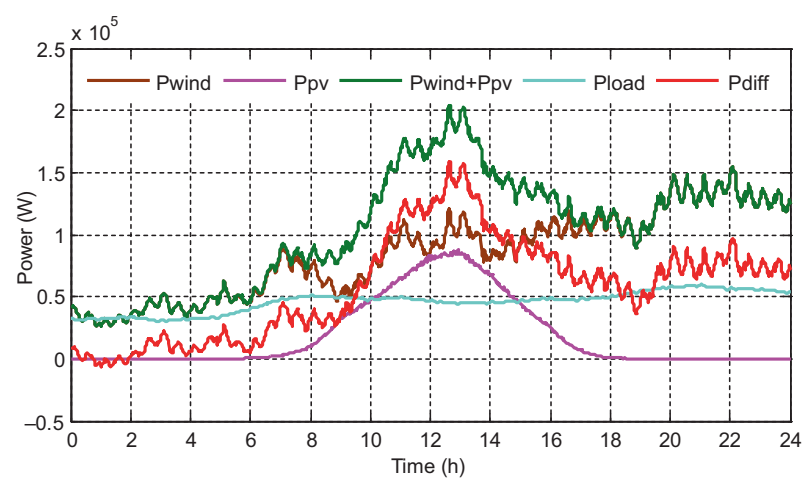

Figure 12. Power trends including wind generator power, solar PV power, total RE power, load demand and excess power.

figure 18, and the algorithm checks $P_{R E S}+P_{F C} \geq L 1+L 2$. This condition is satisfied in the system. Hence, $L 1+L 2$ are supplied with RES + Fuel cell power. During the time $2.50 \mathrm{~h}$ to $21.30 \mathrm{~h}$ the fuel cell delivers the difference in power, At 21.30 the hydrogen pressure goes lower than 4 $\mathrm{MPa}$, so that the fuel cell operation is stopped and load L2 is cut off. The fuel cell power and hydrogen pressure are shown in figure 20(a) and 20(b) respectively. The high priority load L1 need to be supplied without disturbance. For this purpose, the reserved battery energy with SOC less than $70 \%$ is utilized. The battery discharge power and corresponding SOC are shown in figure 19(a) and 19(b). 


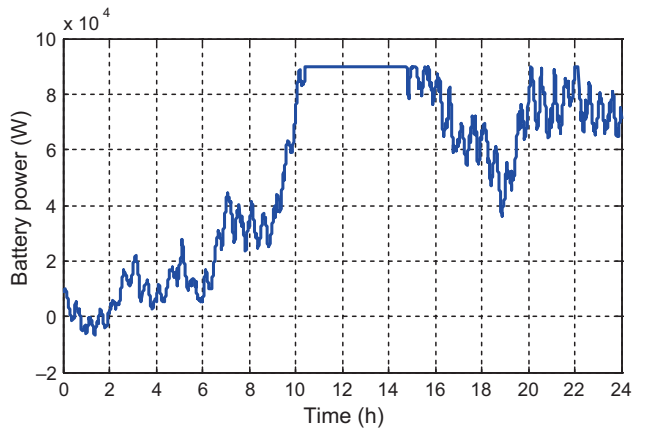

(a)

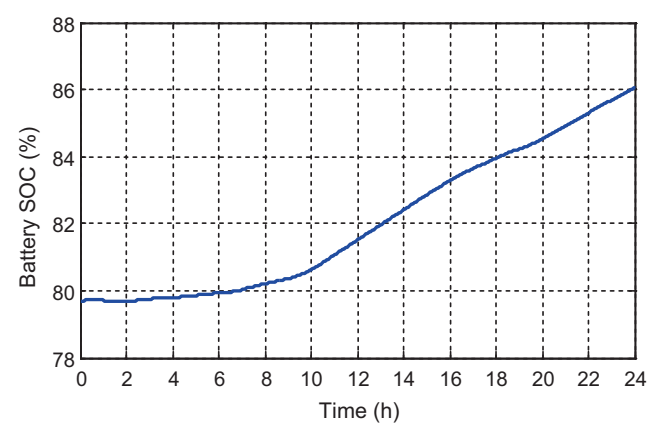

(b)

Figure 13. Battery system (a) power and (b) SOC.

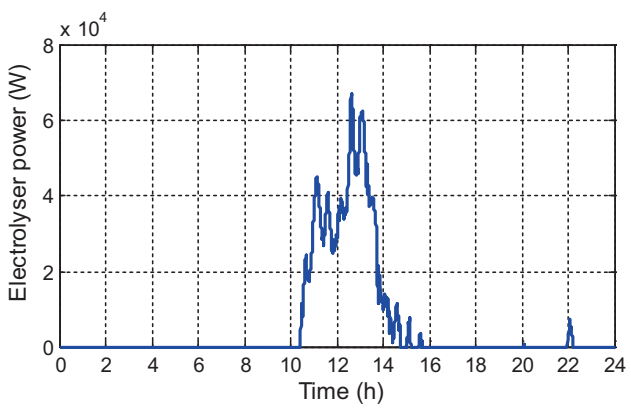

(a)

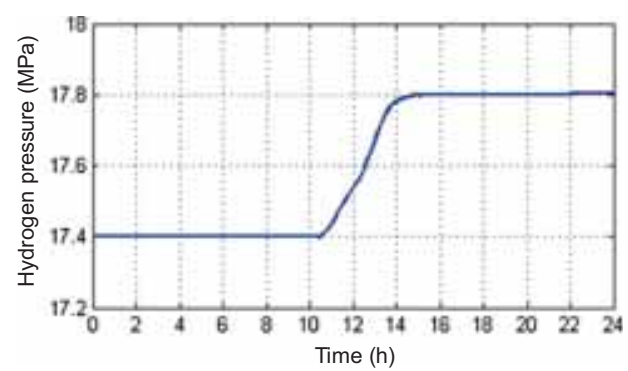

(b)

Figure 14. Electrolyser system (a) power and (b) hydrogen pressure.

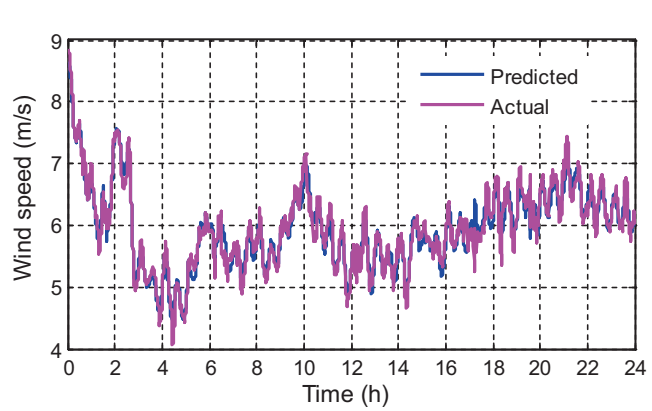

(a)

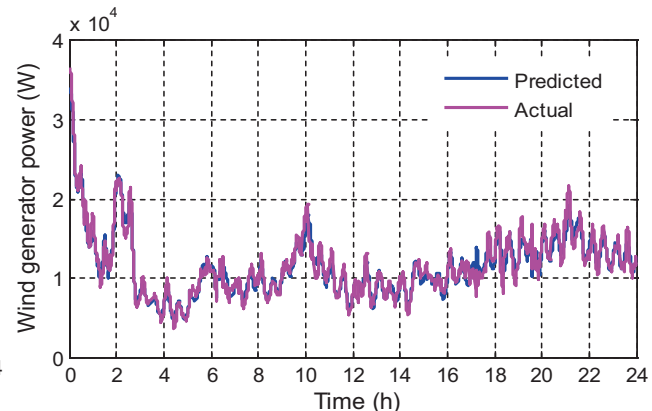

(b)

Figure 15. Wind energy conversion system (a) wind speed variation and (b) generated power.

The load L1 can be supplied by the reserve powers in battery for at least $7 \mathrm{~h}$. This will enable the system to provide power to the high priority load even under worst wind and solar conditions. Also the subsystem ratings have been selected in such a way that the system can handle the load with all type of varying conditions in the system and environment.

The MEMLS algorithm takes necessary decision to meet the base load most of the time in a day and maintains the reserve power in battery during all other conditions, i.e., battery SOC above $70 \%$. A dump load is connected with HPS to protect the wind and solar system during excess power production durations.

The two cases have been considered with wide variation of input parameters such as wind speed, atmospheric temperature, and irradiation. The MEMLS control algorithm using MAS concept that makes decision to control power flow between sources, load and storage system with wide 


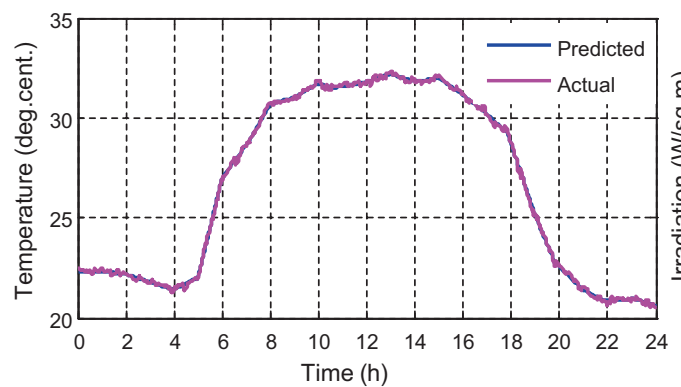

(a)

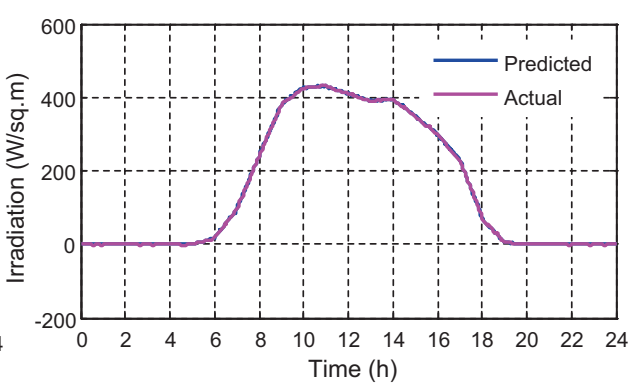

(b)

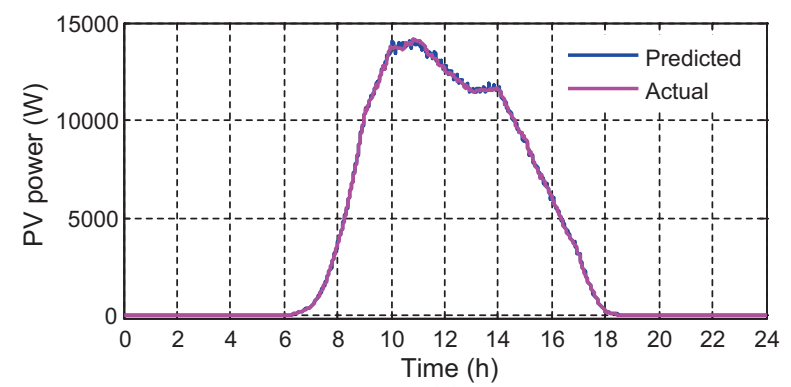

(c)

Figure 16. Solar PV system (a) temperature variation, (b) irradiation level and (c) generated power.

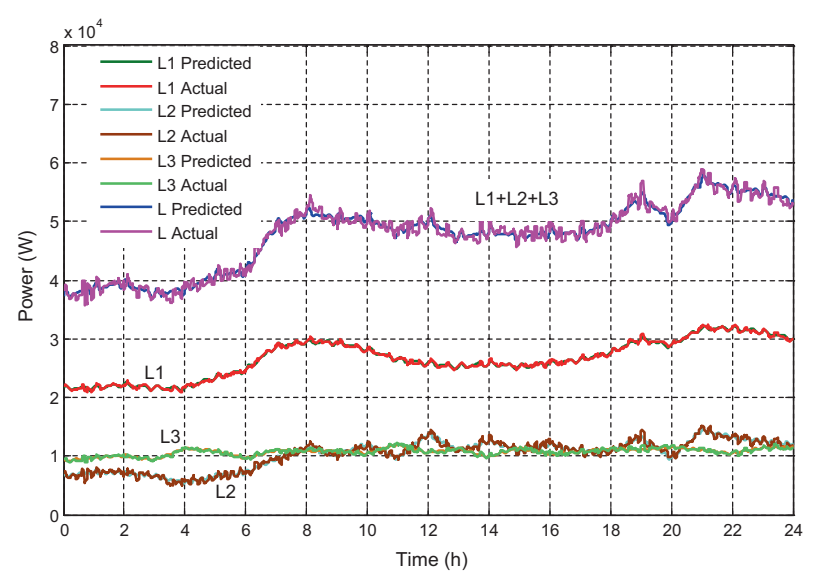

Figure 17. Load power.

variations in RES power production and load. This represents the adaptive nature of the control algorithm in managing the power flow and controlling the load. The MAS algorithm controls each device in HPS with the specified limits set in agents. The MEMLS controller manages the energy flow to the load and storage devices in an adaptive way. The advantage of MAS based algorithm is that it reduces the time delays in making decision, because in classical control all the measurements, calculations and making decisions are done by one controller. But in MAS based system, measurements and control of each subsystem are handled by one agent. MEMLS algorithm thus helps in overcoming the intermittent nature of renewable energy

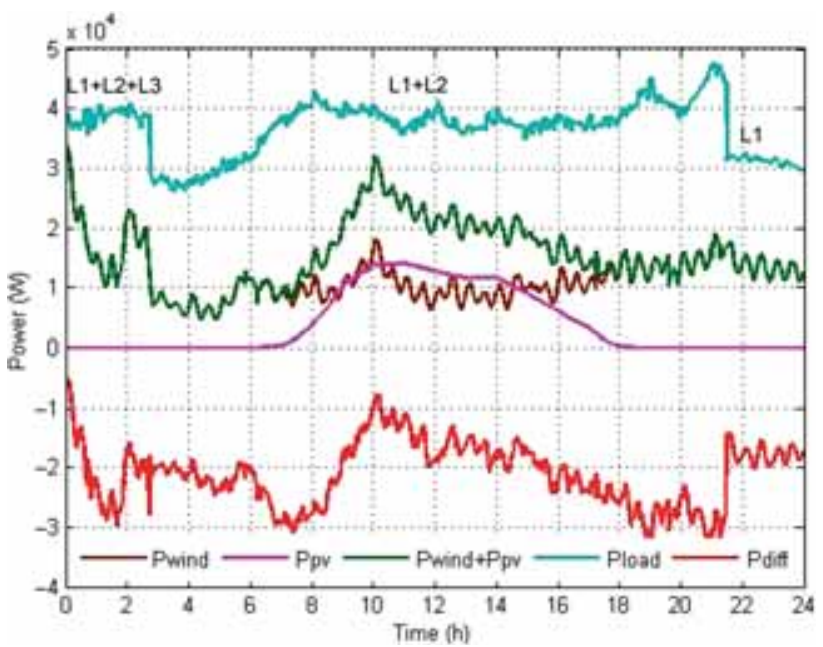

Figure 18. Power trends including wind generator power, solar PV power, total RES power, load demand and deficit power.

sources and still able to achieve a flat load demand for most of the connected load keeping the load shedding minimum. Thus supply integrity and reliability are maintained at high levels most of the time.

\section{Power quality improvement in hybrid microgrid}

The power quality issues in an islanded microgrid are (i) voltage and frequency control, (ii) active and reactive power-sharing control, (iii) harmonic control and (iv) 


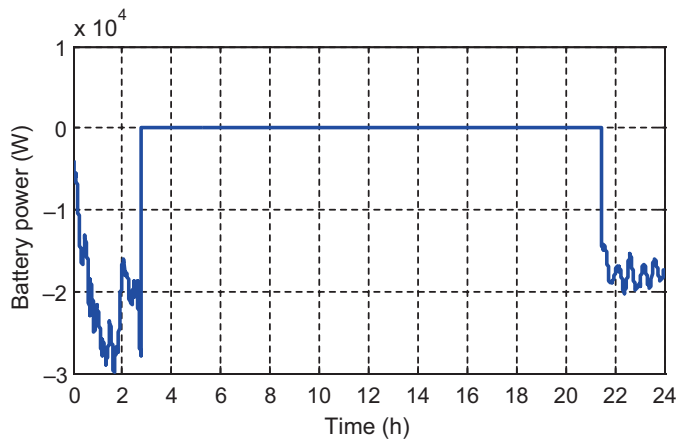

(a)

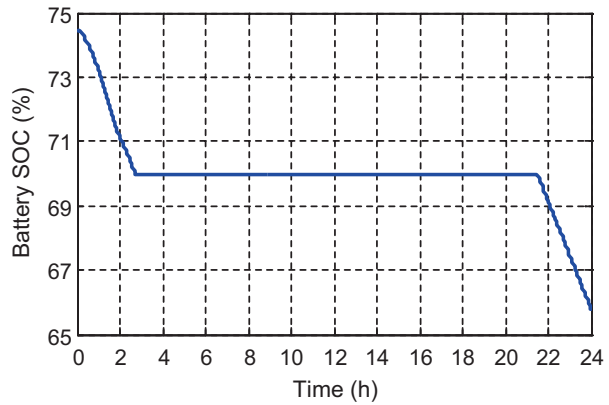

(b)

Figure 19. (a) Battery discharge power and (b) battery SOC.

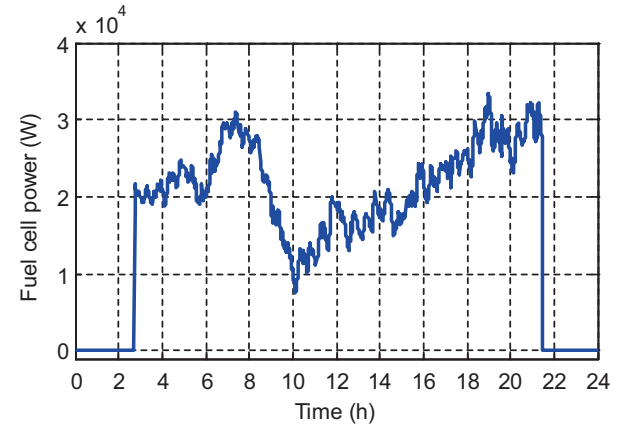

(a)

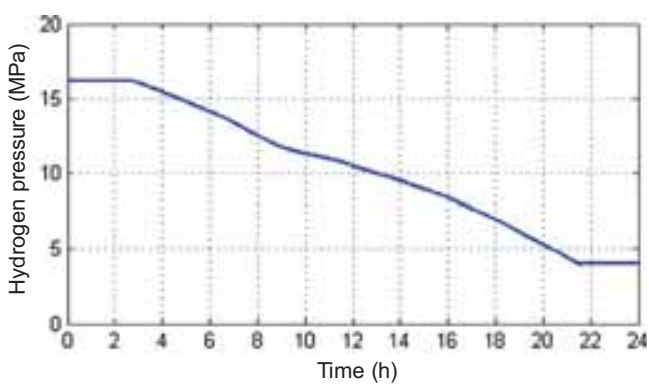

(b)

Figure 20. (a) Fuel cell power and (b) hydrogen pressure.

optimized microgrid operating costs $[6,35]$. The frequency depends on the system active power balance, while voltage variations depend on the system reactive power balance [35]. The frequency control is achieved by matching the source and load powers. A load management controller can achieve frequency control inherently. In order to control the voltage variations and imbalances, reactive power must be balanced in the system by using power electronic compensators [6]. The voltage unbalanced factor (VUF) and the voltage total harmonic distortion (THD) should be maintained below $2 \%$ and 5\% for sensitive loads, respectively according to the IEEE standards [6].

One of the problems in independent HPS is harmonics due to non-linear loads, which affect the shape of source side current and voltage. So that net active power utilization gets affected. The synchronous static compensator (STATCOM) connected with the system will reduce the effect of harmonics by injecting harmonic current into the system and also supply the reactive power demand of the system. In the proposed HPS system a STATCOM $[23,24,36,37]$ is used to regulate the bus voltage and to mitigate the harmonics injected into the system due to nonlinear load. The STATCOM is capable of regulating the bus voltage by absorbing or generating reactive power. In this work an existing model of STATCOM in Matlab (DSTATCOM (detailed model)) [38, 39] with required changes is employed to mitigate both harmonics and reactive power demand (voltage fluctuations).

To show the effectiveness of the STATCOM in the proposed system a $10 \mathrm{~kW}$ nonlinear load (a diode bridge rectifier with $\mathrm{R}$ Load) and linear load of $8.66 \mathrm{~kW}, 5 \mathrm{kVAR}$ are considered. Because of harmonics generated due to nonlinear load, reactive power demand is introduced in the system even though $\mathrm{R}$ load is connected with rectifier. The RL load is connected at $0.2 \mathrm{~s}$ and disconnected at $0.4 \mathrm{~s}$. The real and reactive powers due to the loads with and without STATCOM are shown in figure 21. Between $0 \mathrm{~s}$ and $0.2 \mathrm{~s}$, $0.4 \mathrm{~s}$ and $0.6 \mathrm{~s}$ the reactive power demand is due to nonlinear load. Between $0.2 \mathrm{~s}$ and $0.4 \mathrm{~s}$ the reactive powers are sum of reactive powers due to nonlinear load and RL load. The reactive powers demand is nullified by the STATCOM, which is also shown in figure 21. The load currents with and without STATCOM and the compensating current generated by STATCOM to supply the reactive power are shown in figure 22. The load current magnitude increases at $0.2 \mathrm{~s}$ at which the RL load is connected. The load current is decreased at $0.4 \mathrm{~s}$ at which the RL load is disconnected. The current wave shape is changed to sine form after 

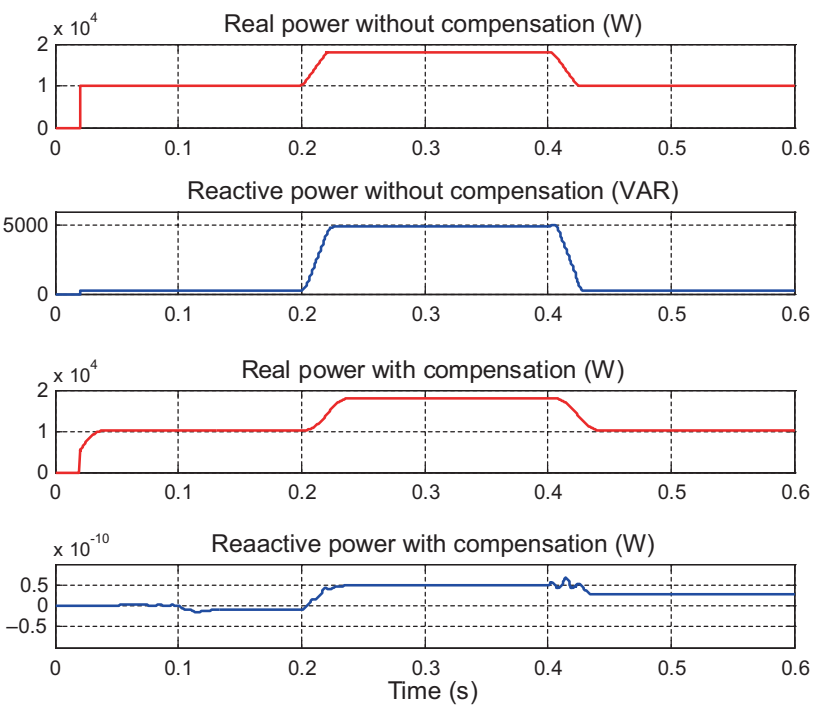

Figure 21. Real and reactive powers with and without STATCOM in HPS.
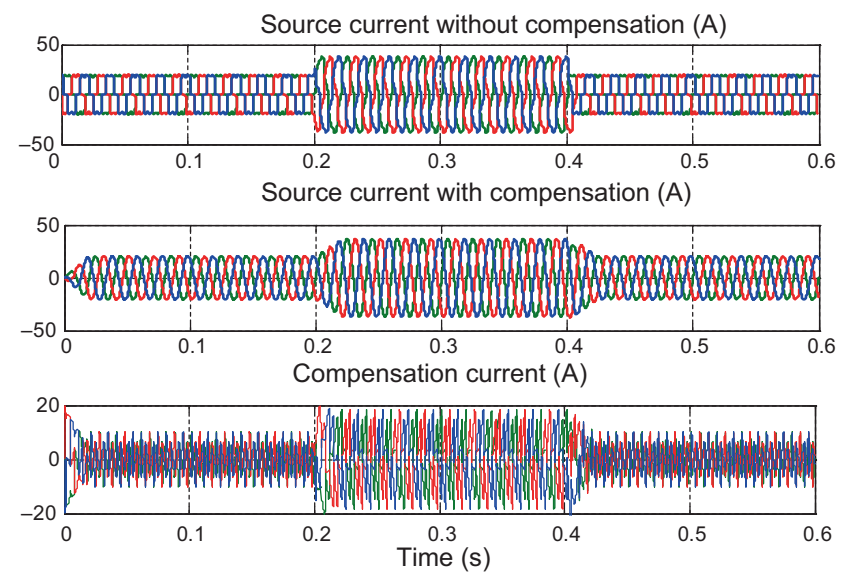

Figure 22. Source current (i) without STATCOM, (ii) with STATCOM, and (iii) compensation current.

Table 2. Source current THD values.

\begin{tabular}{lcc}
\hline Current THD $(\%)$ & $\begin{array}{c}\text { Without } \\
\text { compensation }\end{array}$ & $\begin{array}{c}\text { With } \\
\text { compensation }\end{array}$ \\
\hline With only nonlinear load & 29.97 & 2.83 \\
With nonlinear & 16.17 & 1.57 \\
load + RL load & & \\
\hline
\end{tabular}

compensation. This shows that harmonics are reduced in the load current, which improves the power factor and efficiency of the HPS system. The THD of the source current with nonlinear load is measured as $29.97 \%$ and with nonlinear load and RL Load as $16.17 \%$. After compensation it is reduced to $2.83 \%$ with nonlinear load and $1.57 \%$ with nonlinear load and RL Load. Hence, STATCOM based compensation is effective for the operation of independent HPS microgrid to improve the efficiency and prevent the power quality problems. The THD values found are well below the relevant IEEE standard recommendations (table 2).

\section{Conclusion}

In this paper the proposed MAS technology applied to the energy management in a stand-alone PV/wind/battery/fuel cell HPS microgrid is presented. The simulation model of the hybrid system components, agents and central controller has been implemented in MATLAB/ Simulink. The simulation results are presented for the varying environmental conditions. ARMA models for prediction of solar and wind input data and loads were developed. The environmental conditions are considered on two different days for the analysis of the energy management control algorithm. The proposed control algorithm is able to adapt with continuously varying wind speed, irradiation, temperature, load conditions and achieves the energy management in the microgrid. Also the power quality issues in independent microgrid are addressed by the proposed STATCOM based reactive power compensation. In this paper the load considered is split into three groups only. In the future work, load could be considered with more number of groups and lower power ratings, so that flexibility will increase on load side which will be beneficial to improve the efficiency of renewable energy sources.

\section{References}

[1] Lagorse J, Paire D and Miraoui A 2010 A multi-agent system for energy management of distributed power sources. Renew. Energy 35(1): 174-182

[2] Lagorse J, Simoes M and Miraoui A 2009 A multiagent fuzzy-logic-based energy management of hybrid systems. IEEE Trans. Ind. Appl. 45(6): 2123-2129

[3] Carmeli M, Castelli-Dezza F, Mauri M, Marchegiani G and Rosati D 2012 Control strategies and configurations of hybrid distributed generation systems. Renew. Energy 41: 294-305

[4] Dou C, Liu B and Guerrero J 2014 Event-triggered hybrid control based on multi-agent system for microgrids. IET Gener. Transm. Distrib. 8(12): 1987-1997

[5] Dou X, Quan X, Wu Z, Hu M, Yang K, Yuan J and Wang M 2014 Hybrid multi-agent control in microgrids: framework, models and implementations based on IEC 61850. Energies 8(1): 31-58

[6] Reza Miveh M, Fadli Rahmat M and Asghar Ghadimi A 2015 Power quality improvement in autonomous microgrids using multi-functional voltage source inverters: A comprehensive review. J. Power Electron. 15(4): 1054-1065

[7] Aung H, Khambadkone A, Srinivasan D and Logenthiran T 2010 Agent-based intelligent control for real-time operation of a microgrid. In: IEEE joint international conference on 
power electronics, drives and energy systems. New Delhi, India. 1-6

[8] Mao M, Jin P, Hatziargyriou N and Chang L 2014 Multiagent-based hybrid energy management system for microgrids. IEEE Trans. Sustain. Energy 5(3): 938-946

[9] Abdoul K M, Mamadou L N, Mounirou N and Papa A N 2014 Operation optimal dynamics of a hybrid electrical system: Multi-agent approach. Proc. Comput. Sci. (Elsevier) 36: 454-461

[10] Gi-Gab Y, Won-Pyo H and Ki-Hong L 2011 A multiagentbased hybrid power control and management of distributed power sources. J. Korean Inst. Illumin. Electr. Install. Eng. 25(8): 70-81

[11] Jiang Z 2008 Agent-based power sharing scheme for active hybrid power sources. J. Power Sources 177(1): 231-238

[12] Haruni A, Negnevitsky M and Haque M 2013 A novel operation and control strategy for a standalone hybrid renewable power system. IEEE Trans. Sustain. Energy 4(2): 402-413

[13] Huang R, Huang T and Gadh R 2012 Solar generation prediction using the ARMA model in a laboratory-level microgrid. In: IEEE Third International Conference on Smart Grid Communications, Tainan City, Taiwan: IEEE 528-533

[14] Chang W 2014 A literature review of wind forecasting methods. J. Power Energy Eng. 2: 161-168

[15] Chandra A, Singh B, Singh B and Al-Haddad K 2000 An improved control algorithm of shunt active filter for voltage regulation, harmonic elimination, power-factor correction, and balancing of nonlinear loads. IEEE Trans. Power Electron. 15(3): 495-507

[16] Garcia-Cerrada A, Pinzon-Ardila O, Feliu-Batlle V, Sánchez P R and González P G 2007 Application of a repetitive controller for a three-phase active power filter. IEEE Trans. Power Electron. 22(1): 237-246

[17] George S and Agarwal V 2007 A DSP based optimal algorithm for shunt active filter under nonsinusoidal supply and unbalanced load conditions. IEEE Trans. Power Electron. 22(2): 593-601

[18] Luo A, Peng S and Wu C and Shuai Z 2012 Power electronic hybrid system for load balancing compensation and frequency-selective harmonic suppression. IEEE Trans. Ind. Electron. 59(2): 723-732

[19] Singh B and Solanki J 2009 An implementation of an adaptive control algorithm for a three-phase shunt active filter. IEEE Trans. Ind. Electron. 56(8): 2811-2820

[20] Mehta G and Singh S 2013 Power quality improvement through grid integration of renewable energy sources. IETE J. Res. 59(3): 210-218

[21] Rinchin W, Toko C and Sarsing G 2015 Power quality analysis of hybrid renewable energy system. Cogent Eng. 2(1): $1-17$

[22] Tsao-Tsung M 2012 Power quality enhancement in microgrids using multifunctional DG inverters. In: The International Multiconference of Engineers and Computer Scientists, Vol II, Hong Kong

[23] Vasanthavalli C and Vellaisamy S 2015 Optimization technique for power quality improvement using DSTATCOM. Int. J. Sci. Res. Publ. 4(4): 1-7

[24] Guerrero J, Poh C, Tzung-Lin L and Chandorkar M 2013 Advanced control architectures for intelligent microgrid-part
II: power quality, energy storage, and AC/DC microgrids. IEEE Trans. Ind. Appl. 60(4): 1263-1270

[25] Fatemeh D and Hassan B 2015 Multi-agent systems in control engineering: A survey. J. Control Sci. Eng. 2009: $1-12$

[26] Shu-yun J and Ziang C 2010 Design and implementation of MAS in renewable energy power generation system. In: IEEE Ninth International Conference on Machine Learning and Cybernetics, pp. 22-25. Qingdao, China

[27] Zeng J, Wu J, Liu J, Gao L and Li M 2008 An agent-based approach to renewable energy management in eco-building. In: IEEE International Conference on Sustainable Energy Technologies, pp. 45-50. Singapore

[28] Mohammad A and Shivraj S 2014 Analysis and comparison of various control strategy of hybrid power generation a review. In: 1st International Conference on Nonconventional Energy, pp. 184-189. Kalyani, India: IEEE

[29] Bogaraj T and Kanakaraj J 2012 Development of MATLAB/ Simulink models for PV and wind systems and review on control strategies for hybrid energy systems. Int. Rev. Model. Simul. 5(4): 1701-1709

[30] Kalantar M and Mousavi G S 2010 Dynamic behavior of a stand-alone hybrid power generation system of wind turbine, microturbine, solar array and battery storage. Appl. Energy 87(10): 3051-3064

[31] Dursun E and Kilic O 2012 Comparative evaluation of different power management strategies of a stand-alone PV/ Wind/PEMFC hybrid power system. Int. J. Electr. Power 34(1): 81-89

[32] Roche R, Idoumghar L, Blunier B and Miraoui A 2011 Optimized fuel cell array energy management using multiagent systems. In: IEEE Industry Applications Society Annual Meeting, pp. 1-8. Orlando, Florida, USA

[33] Natsheh E, Natsheh A and Albarbar A 2013 Intelligent controller for managing power flow within standalone hybrid power systems. IET Sci. Meas. Technol. 7(4): 191-200

[34] Milligan M, Schwartz M and Wan Y 2003 Statistical wind power forecasting models: Results for U.S. wind farms. In: Windpower. Austin, USA

[35] Serban I and Marinescu C 2008 Power quality issues in a stand-alone microgrid based on renewable energy. Revue Roumaine Des Sciences Techniques - Serie Électrotechnique Et Énergétique. 53(3): 285-293

[36] Natesan C, Ajithan S, Palani P and Prabaakaran K 2014 Survey on microgrid: Power quality improvement techniques. ISRN Renew. Energy 2014: 1-7

[37] Satyanarayana I, Ballala S, Rama Krishnan V B and Kesani M 2015 Multilevel D-STATCOM for linear and nonlinear loads to compensate reactive and active power during operation of distribution systems. Int. J. Res. Eng. Appl. Sci. 5(8): 98-105

[38] The MathWorks Inc. 2015a STATCOM. Available from: http://in.mathworks.com/help/physmod/sps/examples/d-stat com-detailed-model.html?searchHighlight=STATCOM (accessed 20 September 2015)

[39] The MathWorks Inc. 2015b Time-series model identification MathWorks. Available from: http://in.mathworks.com/help/ ident/ug/bq54wup.html (accessed 22 September 2015) 